\title{
Selma Garrido Pimenta: em defesa de um ensino público e com qualidade
}

Cláudia Nonato

Jornalista, doutora em Ciências da Comunicação pela ECA-USP e editora executiva da Revista Comunicação Ẽ Educação. Professora da FIAM-FAAM e pesquisadora do Centro de Pesquisa em Comunicação e Trabalho (CPCT/ECA-USP).

E-mail: claudia.nonato@uol.com.br

Resumo: Com uma vida totalmente dedicada à educação, Selma Garrido Pimenta é aposentada como professora titular sênior da Faculdade de Educação (FE-USP) e professora assistente no Programa de Pós-Graduação em Educação da Universidade Católica de Santos. Coordena o GEPEFE - Grupo de Estudos e Pesquisas sobre Formação do Educador, junto ao programa de Pós-Graduação em Educação - FEUSP, e acompanha de perto as recentes mudanças na Educação brasileira. Nesta entrevista, realizada em São Paulo, a professora faz uma análise detalhada das Diretrizes Curriculares Nacionais para a Formação Inicial e Continuada dos Profissionais do Magistério da Educação Básica, aprovadas em 2015; além disso, faz uma crítica à privatização da escola pública, à formação de professores, e ao processo de mercantilização do ensino superior no Brasil.

Palavras-chave: Selma Garrido Pimenta; Educação; Diretrizes Curriculares; escola pública; formação de professores.
Abstract: With a life totally dedicated to education, Selma Garrido Pimenta is retired as Senior Professor at the Faculty of Education (FE- USP) and Assistant Professor in the Graduate Program in Education at the Catholic University of Santos. Coordinates the GEPEFE - Group of Studies and Research on Education Educator, with the Graduate Program in Education - FEUSP, and closely follows the recent changes in Brazilian education. In this interview, held in São Paulo, the teacher makes a detailed analysis of the National Curriculum Guidelines for Initial Training and Continuing of the Magisterium of the Basic Education Professionals, adopted in 2015; furthermore, it criticizes the privatization of public schools, teacher training, and the commodification of higher education in Brazil.

Keywords: Selma Garrido Pimenta; Education; Curriculum Guidelines; public school; teacher training.

\section{INTRODUÇÃO}

O Plano Nacional de Educação (PNE) que passou a vigorar em 25 de junho de 2014, com vigência até 24 de junho de 2024, tem como objetivo orientar as políticas educacionais no país para os próximos dez anos e articular a instalação do Sistema Nacional de Educação. Em 2015, foi aprovada a Resolução 
$\mathrm{CNE} / \mathrm{CP} \mathrm{n}^{\circ}$ 2/2015, que define as Diretrizes Curriculares Nacionais (DCNs) para a formação inicial em nível superior (cursos de licenciatura, cursos de formação pedagógica para graduados e cursos de segunda licenciatura) e para a formação continuada.

Essas novas diretrizes curriculares têm sido, sobretudo na Universidade de São Paulo, tema de debates, por conta do seu alcance diversificado, englobando aspectos antes não disciplinados, como o capítulo referente à valorização dos profissionais do magistério para a educação básica, incluindo planos de carreira.

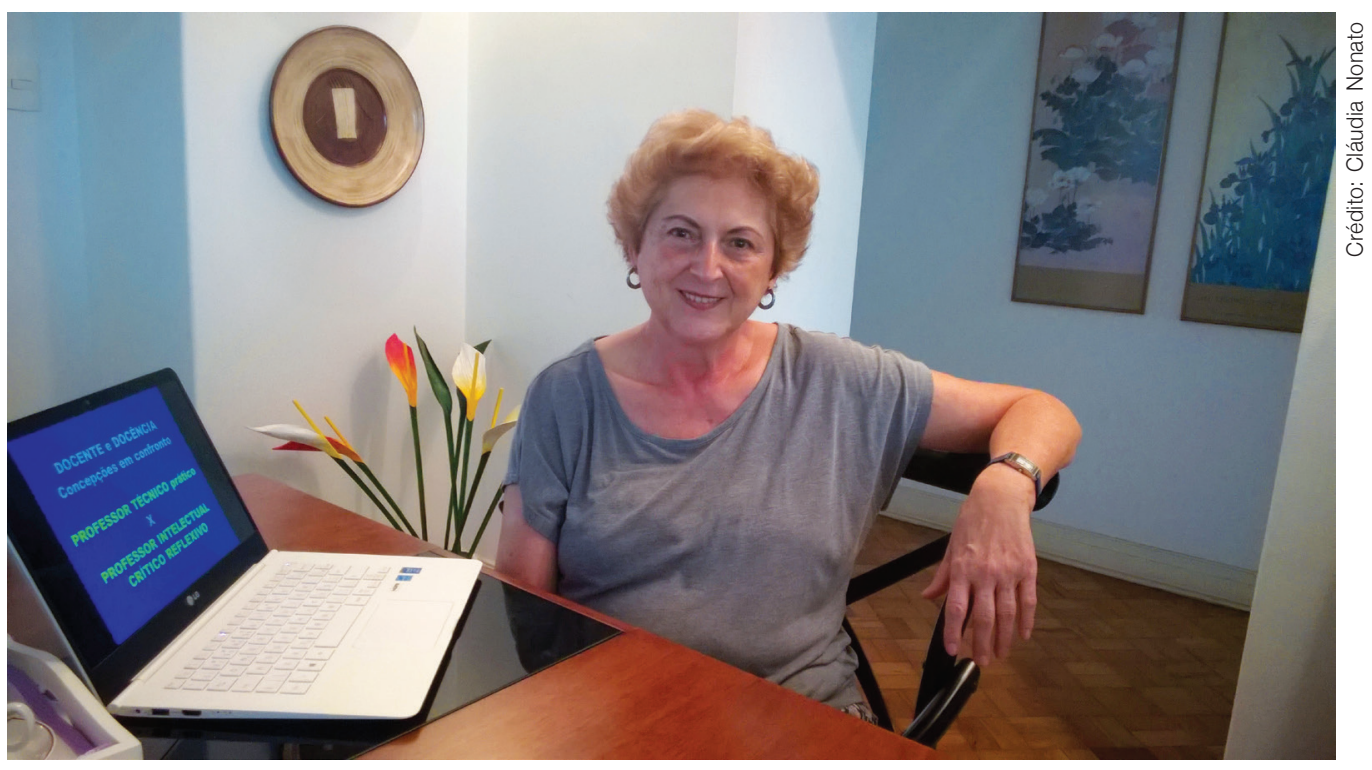

Comunicação $\mathcal{E}$ Educação: Como a senhora avalia as diretrizes curriculares nacionais para a formação inicial e continuada dos profissionais da educação que envolve os professores?

Selma Garrido Pimenta: Eu vou falar sobre a formação inicial e continuada dos professores, porque o Conselho Nacional ainda vai se debruçar sobre a formação dos demais profissionais. Estou acompanhando esse movimento e dei um título nas minhas apresentações e no texto que estou escrevendo sobre o tema: "Seriam essas diretrizes uma ficção acadêmica?". Porque a resolução tem por base um parecer que é, em geral, de natureza teórica, dos princípios da resolução e, esse conjunto, parecer e resolução, são desdobramentos da lei maior que está em vigor, que é o Plano Nacional de Educação, no período 2014-2024. E então por que dei esse título de ficção acadêmica? E, ainda completo, uma ficção acadêmica é uma ficção política? Para situar essas diretrizes curriculares é importante fazer uma breve inferência para o Plano Nacional de Educação. Porque o plano é resultado de um longo processo de elaboração com a participação de muitos componentes da sociedade civil e da sociedade política organizada. E quando nós examinamos quem são os atores que participaram, além do Conselho Nacional, do MEC, dos órgãos de governo, organização dos educadores ou dos gestores, como os secretários municipais da educação do 
país, vimos a participação de um grupo enorme dos setores privatistas; inclusive de fundações de pesquisa, que são dos setores privatistas. Quer dizer: a peça que resultou do PNE é interessante, mas tem que ser examinada no texto e no subtexto, porque é cheia de contradições. Mostrando o resultado desse não consenso, quer dizer, ficou um consenso no texto legal, mas as forças políticas e os interesses - de um lado, dos defensores da escola pública e de outro dos defensores da "mercadorização" ou "financeirização" da educação pública —, então isso não tem acordo, e é por isso que chamei de uma ficção política. Ao mesmo tempo, entrando no tema das Diretrizes Curriculares Nacionais, diria que ela tem um mérito inicial, porque na elaboração das Diretrizes a responsabilidade é do Conselho Nacional da Educação, que tem representantes com assento lá, que são verdadeiramente da academia e dos setores progressistas da academia, e com uma visão muito forte de defesa da escola pública e da formação de professores. Então as contradições são menos presentes do que a do PNE, mas há contradições. Por outro lado, coloquei o título de ficção acadêmica, porque olhando as diretrizes no contexto mais amplo do PNE, nós vemos que, nas suas intenções, o parecer retrata muito o avanço da pesquisa na área da educação, na valorização do trabalho docente, na identificação da identidade do professor, na questão salarial, nas condições de trabalho, nas condições para a formação de qualidade. No entanto, e aí vem o ponto principal da contradição das diretrizes, porque elas são destinadas à formação inicial de professores, além da formação continuada. E nós nos perguntamos: quem forma professores no ensino superior no Brasil? Você tem hoje um número que é bastante assustador, que é do perfil das licenciaturas no Brasil. Com base em dados de 2013 (MEC/Inep), nós tínhamos 7.900 cursos de licenciatura no país; desses, $55 \%$ públicos e $45 \%$ privados, a maioria presenciais. Mas, quando a gente olha esse dado das matrículas e dos ingressantes é que a coisa fica assustadora, porque o setor privatista domina 54\% das matrículas, sendo a maioria das privadas em EAD (Ensino à Distância). E fica mais evidente que a licenciatura está nas mãos do setor privatista quando você olha o número de alunos ingressantes, 68\% nas privadas, e de concluintes, 64\%, sendo que desse número $88 \%$ são em cursos EAD. Então, se você retira desse conjunto das privadas no Brasil algumas que são ainda confessionais ou comunitárias e que têm uma tradição, instituições antigas, como as Católicas de São Paulo, de Santos, de Goiás, de vários lugares, têm uma tradição de formação de professores, e não podemos colocar as privadas todas no mesmo patamar; assim como no sul do país temos muitas instituições que são efetivamente comunitárias, e têm projetos de sociedade e formação interessantes. Quando nós falamos das privadas, e são essas as que detêm a maioria da formação dos professores, nos referimos às instituições chamadas financistas, que são aglomerados empresariais com capital internacional e que fazem parte do mercado de capitais no Brasil. Esses conglomerados estão comprando as pequenas particulares que existiam e a partir daí percebemos que há uma questão muito concreta e muito difícil. E essas diretrizes orientarão a maioria dessas instituições; só que estas têm 
mecanismos para se adequar às diretrizes, modificando inclusive os conceitos, posturas e valores que estão expressos no parecer das atuais diretrizes. Foi por isso que chamei de uma peça de ficção; não é tanto o texto legal em si, mas é o texto em confronto com essa realidade.

Essas diretrizes apontam algumas questões interessantes. A primeira delas se projeta como formação inicial e continuada dos professores, pois até há pouco as diretrizes anteriores não faziam referência à educação continuada e isso é importante porque a universidade poderá ter uma proximidade maior com as escolas da educação básica para a formação continuada dos professores e, ao mesmo tempo, para a formação continuada dos próprios professores da universidade, que terão mais oportunidades de conhecer e pesquisar a escola pública. Então ela tem aspectos que são importantes, como uma clara explicitação sobre as concepções de uma educação emancipatória, com clara influência freiriana [Paulo Freire]. Do professor como um profissional que tem que ser formado de modo crítico, analítico, com compromisso social e político, ou como nós denominamos um professor que seja intelectual crítico reflexivo. Eu tenho pesquisas sobre alunos egressos da USP, de licenciatura, e percebemos que quando o aluno tem uma boa formação teórica, consegue enfrentar melhor e mesmo propor caminhos para situações problemáticas que encontra na realidade. Em oposição, esse setor privatista tem a concepção de professor, que é de um técnico que reproduz os conteúdos de apostilas feitas por esses mesmos setores privatistas e vendidas para os sistemas públicos. É uma forma de o público do sistema público gratuito e estatal ser corrompido e se deixar corromper, porque é uma relação de mão dupla, para se desobrigar da sua obrigatoriedade da garantia de direito a uma formação e entrar nesse sistema abrindo para o setor privatista. Outro ponto importante das diretrizes é que ela amplia a carga horária, que antes era mínima de 2.800 horas, e passa para 3.200 horas, e a compreensão de que o professor tem que ser formado de modo a que ele também compreenda o espaço onde se situa, a sala de aula no contexto da escola, do trabalho coletivo, portanto envolvendo os conhecimentos pedagógicos e educacionais, e que possibilitem que o professor saiba o que é um Projeto Político Pedagógico do currículo, para que faça da sua disciplina, das suas aulas, numa percepção de relação ampliada com os demais colegas, porque a formação, o aluno é o mesmo, os professores é que são vários. Essa perspectiva de trabalho coletivo e projetos interdisciplinares, essa diretriz valoriza bastante isso. Outra questão muito importante para o Brasil, é que essa diretriz define claramente que a formação de professores para a educação infantil e para o fundamental I, terá uma licenciatura própria que é o curso de pedagogia, porque antes a formação para esses professores estava separada das diretrizes curriculares nacionais e agora está dentro. É uma clara articulação entre a formação teórica e as práticas escolares contextualizadas e, ao longo do processo de formação, ou seja, uma relação bem próxima com a escola pública na qual o aluno, futuro professor, vai se inserir provavelmente. No restante ela redistribui essa carga horária, entre o que denomina Prática como Componente Curricular, com 400 horas, mais 
400 horas de estágio supervisionado (que foi aumentada em relação à diretriz de 2002) e 1.200 dedicadas aos conteúdos das áreas específicas, incluindo as do campo educacional, e umas 200 horas de atividades culturais, conforme os interesses dos estudantes. Porém uma coisa que eu acho que foi uma falha dessas diretrizes é que as diretrizes anteriores, de 2002, definiram essa mesma nomenclatura, e as instituições fizeram o que bem entenderam com esse componente curricular chamado "Prática como Componente Curricular". Eu acho que faltou ao CNE, uma base de pesquisa para ver o que aconteceu no Brasil afora porque acho que permanece esse problema de a instituição colocar o que ela bem entende; no seu projeto institucional ela inventa e pode até se desincumbir de, na realidade, fazer acontecer. Também acho que tem um problema que é o próprio estágio. Eu teria retirado essa nomenclatura Prática como Componente Curricular e teria colocado simplesmente o Estágio Supervisionado com 800 horas. A manutenção do componente Práticas como Componente Curricular, permite que as instituições usem a própria lei para diminuição de seus gastos, em última instância. Já a definição dos estágios com 800 horas, poderia evitar esse desperdício que as instituições financistas queiram fazer.

$C \mathcal{E}^{2} E$ : Quais são as demandas para a formação de professores no Brasil? $\mathrm{E}$ os principais problemas dos cursos de formação dos professores?

SGP: A demanda está relacionada com o trabalho, com as condições de trabalho e a questão salarial incluída, de modo geral. Eu não tenho os números exatos aqui, mas a faixa do fundamental I, com os seis anos iniciais, tem professores em quantidade suficiente, formados, a maioria, em ensino superior. A etapa anterior, que é a da pré-escola de educação infantil, não há professores em quantidade suficiente formados em nível superior, porque persiste, ainda, um entendimento, de que o cuidado da criança pequena não é um trabalho de educação, e, portanto, não precisa de profissionais formados para desenvolvê-lo. Esse entendimento camufla um real problema que é o de estados e municípios não precisarem investir nesse nível de escolaridade. O segmento do fundamental II e o do ensino médio é onde encontramos, especialmente no ensino médio, uma deficiência maior de professores e é aí que se expressa uma contradição que tem duas disciplinas que evidenciam isso: química e física, porque o número de formados no país para essas disciplinas ultrapassa a necessidade das redes; no entanto, é onde mais falta esses professores. Há vários estudos demostrando mas principalmente porque para essas áreas o licenciado que fez bacharelado e licenciatura tem outras possibilidades de emprego que são mais rentáveis, e a escola não atrai. É o sistema, que bate nas questões das condições de trabalho, nas questões salariais e ausência de carreira. A legislação, tanto esta aqui [as DCN] quanto o PNE, está colocando a necessidade do plano de carreira em todos os sistemas públicos, estaduais e municipais. No estado de São Paulo, por exemplo, até há um plano de carreira, no entanto, a forma como ele está sendo burlado pela própria Secretaria da Educação é horrível. Ela faz concurso, mas 
chama o professor concursado depois de três anos; nesse período ele tem que trabalhar em outra coisa. Além disso, está muito presente essa forma de considerar um professor bom pela avaliação dos alunos ou pelo resultado destes, no caso da educação básica; se o resultado dos alunos não é bom, o culpado é o professor, dizem, e se é bom, ele vai ganhar um abono, que não é salário. É um pouco essa lógica do capital que interfere muito na formação dos professores, mas que não dá para separar das condições de trabalho. Por outro lado, uma observação que esqueci, é que as atuais diretrizes preveem, conhecendo um pouco esse quadro, o que chama de formação inicial, a primeira licenciatura, segunda licenciatura, ou seja, o professor que está em exercício e que está dando aula de matemática, mas é formado em história, ele poderá fazer uma segunda licenciatura enquanto está atuando; e a licenciatura para quem é só bacharel. Tem um fenômeno que acontece é que profissionais de outras áreas estão atuando como professores, por exemplo, bacharéis em direito que estão dando aula de português; ou engenheiros dando aula de física. Ele não tem licenciatura, e a legislação prevê a formação deles dessa forma, para regular esse sistema. Em geral, esses profissionais não encontram trabalho em suas áreas de formação, ou são aposentados que se oferecem para cumprir algumas aulinhas.

\section{$C \mathcal{E}^{\circ} E$ : Como podemos relacionar o programa da USP de formação de professo- res com as diretrizes nacionais para a formação de profissionais da educação?}

SGP: O programa é fruto de um longo processo, porque quando a USP foi criada, em 1934, um dos objetivos principais era formar professores para o sistema público de ensino no estado de São Paulo. No entanto, ao longo do tempo, essa formação de professores foi sofrendo um desprestígio na universidade porque ela caminhou muito como uma universidade de pesquisa e a formação para o ensino foi perdendo um pouco o significado e importância. No entanto, desde a década de 1980 aproximadamente, as Prós-Reitorias de Graduação assumiram um projeto que foi sendo elaborado com a participação de todas as unidades da USP e formatou, em 2004, um programa novo muito interessante e que em parte conversa com as atuais diretrizes. Eu digo até que o programa da USP (PFPUSP) foi sendo referência para outras universidades que sofreram desse mesmo problema, em que a licenciatura vinha perdendo prestígio em função desse quadro de realidade do trabalho docente não ser valorizado na sociedade de modo geral. Então esse programa tem uma clara concepção da formação dos professores, pois articula a Faculdade de Educação e os institutos da universidade que oferecem licenciaturas, além dos bacharelados, que são correspondentes às disciplinas que formam o currículo da educação básica. Esse programa valoriza muito o estágio e a relação do estágio com a rede pública. Enfim, ele tem uma série de características que aproximam muito dessas atuais diretrizes, e eu até arriscaria dizer que muito do que nela está, foi contribuição desse programa. Afinal, nós temos uma atividade docente que não se restringe à USP, porque participamos em várias associações da área. Eu 
fui uma das Pró-Reitoras de Graduação que consolidou o PFPUSP; sou muito ligada à nossa Associação Nacional de Pesquisa e Pós-Graduação em Educação e a associações que se voltam diretamente para a formação de professores, as minhas pesquisas são dessa área e do meu grupo, e assim como eu e vários colegas do Brasil, que fizeram essas diretrizes, somos interlocutores de longa data. A USP pode se fortalecer mais ainda com as atuais diretrizes, e digo que ela pode porque a USP está sofrendo um processo de privatização. E nós vamos vendo que esse setor da formação de professores, se está relativamente forte em todas as Unidades, cada reitoria que chega tem um projeto diferente. E a atual está com projetos que altera o coração dessa proposta, que é o projeto institucional conjunto de todas as licenciaturas. Esse coração é a CIL (Comissão Interunidade de Licenciaturas), que é uma comissão que assessora o Conselho de Graduação, portanto, que assessora o(a) Pró-Reitor(a), no que se refere às licenciaturas. Se, de um lado nós temos um reforço para o projeto da USP que vem com essas diretrizes nacionais, do ponto de vista interno à universidade, estamos tendo problemas com a atual reitoria, que não valoriza a formação de professores como acontece em vários outros espaços. Nós estamos num momento de muitas tensões, mas tenho acompanhado vários movimentos dos educadores, que são alunos da pós-graduação e professores de escolas públicas que a USP contrata para fazer a mediação entre os cursos de licenciatura e a escolas conveniadas. E esse trabalho tem sido muito interessante, mas que corre o risco de desaparecer.

\section{$C \mathcal{E}^{\circ} E$ : A educação a distância pode se configurar em uma solução para a falta de professores bem preparados? \\ SGP: Não. Uma coisa é a EAD como complemento da formação de profes-} sores; é diferente usar a tecnologia e informática como suportes, isso é desejável, e substituir a formação presencial. Porque a formação inicial tem que ser um processo de análise, de troca, de busca de elementos, de dados, tem que ser diálogo, reflexão conjunta, coletiva, tem que colocar o aluno no universo do exercício profissional, isso significa desenvolver pesquisa da realidade, para compreender, para analisar, para fazer uma análise crítica consistente, apontar caminhos e possibilidades. E essas questões todas não estão prontas, porque o ensino acontece em contextos situados, portanto com todas as interferências desses contextos, se o professor não se apropria disso de uma forma crítica e reflexiva, não tem como, e isso não dá para fazer na EAD. Há algumas instituições, como a Universidade Federal de São Carlos, que tem um belo programa de formação a distância, mas entre o risco que corremos e já está expresso por esses números que mostrei, de a EAD ser cada vez mais uma solução "barata" para formar esse professor técnico, executor meramente, sem teoria, que é o que os setores privatistas dizem: professor não precisa ter teoria em sua formação. Então eu acho que temos que combater a EAD como substituição da presencial, porque vivemos nesse contexto da lógica (e do poder) dos setores financistas. 
comunicação \& educação • Ano XXI • número 1 • jan/jun 2016

$C \mathcal{E}{ }^{2} E$ : Em manifestação recente, a secretária de Educação, Cultura e Esporte de Goiás, Raquel Teixeira, informou que em 2016 cerca de 250 escolas de ensino básico do estado serão geridas por organizações sociais do terceiro setor. Qual a avaliação da senhora acerca desse modelo de gestão das escolas, cogitada em vários estados brasileiros e mesmo no plano federal, via parcerias público-privadas ou OSCIPS?

SGP: Essas políticas das escolas que são chamadas de charter são péssimas. Eu diria que é a vitória dos setores financistas, porque ela significa apenas a transferência de verba pública para o setor privado, e essa concepção de formação de professor é a que está presidindo essas escolas. Ela vem dos Estados Unidos, onde o setor privatista funciona em paralelo às universidades, não são cursos superiores, são cursos de formação aligeirada de professores, e não são formação em nível superior. No Brasil, essas instituições não conseguiram criar esse sistema paralelo como existe nos Estados Unidos; por isso, o caminho que encontraram foi o de comprar as escolas superiores de formação de professores, garantindo ali o mercado delas na formação. E agora estão garantindo o seu mercado de inserção desses alunos egressos dessas instituições, para que eles possam ter acesso como professores nessas escolas. E essas escolas têm inicialmente uma equipe da própria empresa, que vai assumindo o trabalho que os professores deveriam fazer. É um trabalho de privatização da escola, e os resultados que eles vão mostrando - pegam duas, três escolas que os alunos aprendem, sendo que apenas parte deles aprende não são todos — não é o de uma escola que tem uma perspectiva pública, de direito à educação e inclusão, mas de uma escola que vai aumentar a exclusão, porque essas empresas não têm interesse em que todos os alunos tenham esse direito garantido e assegurado. Então o estado de Goiás vai ser um paradigma dessa privatização, que ocorre por dentro do sistema público e com verbas públicas e com a conivência do Ministério da Educação. E isso é muito triste. Nos Estados Unidos ao menos você tem uma garantia de que essas escolas, no caso de formação de professores, não concorrem no mesmo nível com a formação nas universidades. Aqui você percebe que esses setores estão fechando um ciclo do capital, é uma geração de lucro, uma capitalização cada vez mais aprimorada do capitalismo e da exclusão social. Com essa lógica que esse professor, no caso, tem uma identidade frágil, ele até vai mudando de nome, a Fundação Carlos Chagas, por exemplo, chama o professor de "agente institucional de ensino", ele não é mais professor. O que é isso? Eles são executores dos scripts produzidos por agentes externos, que são apostilas ou mercado editorial que eles também têm, vários desses conglomerados têm sua própria editora, como no caso a Abril Educação, que é um desses órgãos, e o professor fica reduzido a uma habilidade do fazer, ausência de teoria, redução à prática. Professores para os filhos dos outros, ou seja, para os pobres que estão na escola pública, e professores com um estatuto profissional precário, ele é contratado por um tempo determinado, podendo ser descartável, na hora que o sistema quiser. Então, é essa minha avaliação, inclusive a imprensa está apontando aspectos muito negativos da escola charter 
de Goiás, e o principal deles, a meu ver é que é uma escola excludente, e não de garantia de direitos, e de privatização dos recursos públicos para interesse desse capital.

$C \mathcal{E}$ E: Existem afirmativas, por membros do Conselho Estadual de São Paulo, que os cursos de licenciatura são teóricos demais, deixando de lado a dimensão prática da formação docente para ao exercício do magistério. Esse tipo de afirmativa faz sentido?

SGP: Quem são os componentes do Conselho Estadual de Educação de São Paulo? Quais são as origens deles? Eles são donos de conglomerados, têm duas pessoas que são membros da Kroton, membros da Fundação Lemann e donos de escolas particulares de São Paulo que estão vinculadas aos setores privatistas. Então, o Conselho Estadual de Educação de São Paulo está privatizado, é um órgão de interesse desses setores financistas da educação. E as críticas que eles fazem às universidades, porque ainda não conseguiram demolir as universidades públicas, são com esses interesses. Dizer que a formação nas universidades é teórica é um equívoco, mais do que isso, um interesse de que o professor seja prático sem teoria, um professor que não pergunta, que não questiona, que não propõe, que não pesquisa, que se submete a condições precárias de trabalho. A universidade, até onde pode está resistindo, inclusive essa nossa pesquisa com os egressos das licenciaturas da USP de um período largo (2005 a 2008), mostra, coincidindo com pesquisas em outros países, que os professores formados em boas instituições até vão para as escolas públicas, mas o próprio sistema público privatizado vai dando um jeito de expulsá-los da profissão; então ficam pouquíssimo tempo, quando conseguem sequer ficar. Esse é o fator que marca o atual conselho, que não é de hoje que está assim, vem sendo privatizado há pelo menos duas décadas. Por outro lado, você tem movimentos internos da universidade que caminham também nessa direção, estamos quase numa guerra.

$C \mathcal{E} E$ : A senhora poderia comentar a reação dos jovens estudantes do ensino básico ao projeto do governo do estado de São Paulo, de promover uma reorganização escolar?

SGP: Antes de mais nada, quero dizer que foi um alento para nós vermos a beleza desse movimento, porque esse projeto não tem uma intencionalidade educacional, tem intencionalidade financeira, a de reduzir o gasto com educação, com as escolas públicas frequentadas em sua maioria pelos estudantes pobres ou de baixa renda. E por que São Paulo? Porque é uma das maiores redes do mundo, tem essa dimensão enorme, e o governo do estado colocou na Secretaria da Educação também pessoas que são do Conselho Estadual e da própria Secretaria da Educação, que são os formuladores dessa proposta de redução das escolas. Essa redução é, no mínimo, um contrassenso, porque nós, 
educadores, conseguimos, após os últimos cinquenta anos de lutas, ampliar a escola pública no Brasil — quando eu estudei [décadas de 1950 e 1960 em São Paulo], por exemplo, fiz o primário na pública, mas o ginásio, tive que fazer na escola particular, porque no meu bairro, não havia escola pública — assim como não havia escola pública para todos que se encontravam em idade escolar. $\mathrm{Na}$ década de 1930, tivemos no país o movimento dos Pioneiros da Educação Nova, com Anísio Teixeira, por exemplo, que foi um dos principais educadores nessa luta para expandir a educação pública. Depois, nos anos 1960, na sequência daquele, tivemos o movimento que foi denominado de "Pioneiros da Educação: mais uma vez convocados", com intelectuais como Florestan Fernandes, mais para a frente, com o Paulo Freire, e na década de 1980 o movimento dos educadores reunidos nas Conferências Brasileiras da Educação, que realizadas diretamente por associações dos educadores, sobretudo Anped [Associação Nacional de Pós-Graduação e Pesquisa em Educação], vinculadas às universidades. Nesses mais de cinquenta anos, conseguimos ampliar o número de escola públicas no Brasil, e, agora, o governo do estado de São Paulo quer reduzi-las, e qual o argumento que ele tem lá na base, que tanto a secretaria como o governador tem falado, é que houve uma redução de matrículas nas escolas, o que é verdade, houve uma redução, mas porque há uma evasão de alunos e professores. No último ano, São Paulo teve o maior número de professores que pediram para ser exonerados, mais de 11 mil, um recorde histórico, porque o tratamento em relação aos professores é um descalabro, é um tratamento de um estatuto precário da profissão, então saem, e, por outro lado, os estudantes que em grande parte vêm das classes mais baixas financeiramente da população. Nos últimos anos, houve uma efetiva diminuição da miséria, o Brasil progrediu, avançou, elevou uma população a um segmento maior socioeconômico e, desse segmento, você tem uma grande parte de classe média que está profundamente insatisfeita com o tratamento que seus filhos recebem em escola pública, e que encontraram alguma forma, estão se matando para pagar uma escola particular, que nem sempre é boa. Você tem nessa política do governo do estado nos últimos vinte anos, a construção de uma representação social de que a escola pública não é boa, e então houve uma redução nas matrículas. O que a Secretaria da Educação nesses vinte anos tem feito para agravar esse quadro? Ela é a responsável. Agora vem com uma pseudosolução de reduzir o número de escolas que estão com vagas sobrando, e quando você examina o projeto, vê que essas crianças vão ser amontoadas em classes. Nos países em que a educação tem dado certo, há um consenso de que o máximo de vinte alunos por sala no ensino fundamental é o desejável, e, no máximo, trinta no ensino médio e, no início da escolarização, quinze; o que garante um ensino e educação de qualidade. Mas o governo do estado de São Paulo é aliado a esse setor privatista. O movimento dos alunos está sendo fantástico e foi importante mostrarem que o governador foi obrigado a suspender o projeto, demitiu o secretário, mas não demitiu as pessoas que assessoravam o secretário, que são essas que eu apontei que estão também no Conselho Estadual da Educação. Ele tapou o sol com a peneira, 
apenas suspendeu o projeto. E eu vi um dos estudantes no meio do movimento dizer que "suspender não é retirar", fazendo um paralelo com a situação de que quando você está na escola, pode ser suspenso ou expulso, quer dizer o suspenso retorna e o expulso sai da escola. Os estudantes compreenderam direitinho, o governador suspendeu, mas não retirou o projeto. E com esse grupo que o assessora o governador vai continuar mexendo para ver como ele implementa isso de um jeito menos traumático do que esse que apareceu na mídia, só que o problema vai permanecer, e certamente eles tomarão providências para interferir nesse movimento, de modo que ele vá se esgarçando. É uma tragédia.

\section{$C \mathcal{E} E$ : É possível superar e reverter essa situação?}

SGP: É possível, sim, com o movimento da sociedade civil organizada, o movimento dos estudantes mostrou que é possível. E também foram muito firmes em mostrar que o movimento era deles e não de partidos, grupos ou sindicatos. Além dessa areia que colocaram nessa engrenagem, eu acho que o saldo mais bonito é ver que na rede pública, com todas essas questões, eles são capazes de pensar; estão fazendo uma análise crítica, de alguma forma, e os professores estão conseguindo formá-los para pensar, ver o contexto em que vivem na relação com a sociedade. Eles mostraram que são sujeitos coletivos, pensando coletivamente. A guerra que nós estamos enfrentando é contra a razão, contra o pensar, contra o sujeito coletivo, contra a emancipação da sociedade. Mas aqui o que estamos vendo é claramente um avanço de um capitalismo cada vez mais predador, que expulsa, que tem no consumo o único valor, e isso impregnado nos meios de comunicação, no jornalismo. E daqui a cinquenta anos, como vai ser? Ainda bem que sempre há brechas e saídas. O que estamos vivendo no país hoje é a expressão de contradições, e o que vai sair dessas contradições que estão em confronto, cada um de nós está investindo na possibilidade de um Estado cada vez mais público-estatal, embora estejamos assistindo à privatização do Estado público na parceria público-privado. Claro que eu tenho esperanças, às vezes eu fico um pouco assim, "será?", mas eu lembro que tenho 72 anos, e a minha esperança é um pouco menor. Só que ainda não entreguei os pontos. Eu me senti emocionada de ver esse movimento de jovens. Teve um dia que eu amanheci às lágrimas, chorei tanto, porque sentia um misto desses sentimentos todos, uma esperança concreta nessa moçada. E são de escola pública, que estão só defendendo seu direito de estudar, que é um DIREITO, e não uma mercadoria que estão comprando. Embora Goiás esteja se equipando para doar a mercadoria, por enquanto, ela não vai cobrar dos alunos, mas daqui a pouco vai inventar forma de o aluno pagar para estar nas escolas - charter. Quiçá os pais de Goiás e os estudantes percebam essas dimensões e façam um movimento como aconteceu aqui, em São Paulo. 